\title{
Effects of nutriental and environmental conditions on carotenoid biosynthesis by Rhodotorula sp.
}

\author{
Ly Thi Minh Hien ${ }^{1}$, Dong Thi Anh Dao ${ }^{2}$ \\ ${ }^{1}$ Ho Chi Minh City Open University, Vietnam \\ ${ }^{2}$ Ho Chi Minh City University of Technology, Vietnam National University HCMC, Vietnam \\ *Corresponding author: hien.ltm@ou.edu.vn
}

\begin{tabular}{|c|c|}
\hline ARTICLE INFO & ABSTRACT \\
\hline $\begin{array}{l}\text { DOI: } 10.46223 / \text { HCMCOUJS. } \\
\text { tech.en.8.2.343.2018 }\end{array}$ & $\begin{array}{l}\text { Carotenoid compounds are popular natural antioxidants } \\
\text { which are commonly isolated from the plants. Recently, there } \\
\text { have been many researches on carotenoid biosynthesis towards } \\
\text { low cost products. In this study, Rhodotorula sp. was grown on an } \\
\text { agricultural byproduct (corncobs) as a matrix in solid-state } \\
\text { fermentation. Essential nutrients were added with different }\end{array}$ \\
\hline Received: February $6^{\text {th }}, 2018$ & concentrations to optimize condition for the carotenoid \\
\hline Revised: April $8^{\text {th }}, 2018$ & biosynthesis. Effects of other environmental factors such as \\
\hline Accepted: May $14^{\text {th }}, 2018$ & $\begin{array}{l}\text { moracterized. The optimal nutrient composition for the yeast's } \\
\text { growth and carotenoid biosynthesis is a compound of } 500 \mu \mathrm{g} \\
\text { nitrogen and } 16 \mathrm{mg} \text { carbon in } 100 \mathrm{~g} \text { matrix. Additionally, the }\end{array}$ \\
\hline Keywords: & moisture content of $80 \%$ is the best for producing carotenoid by \\
\hline $\begin{array}{l}\text { Biosynthesis, carotenoid, } \\
\text { Rhodotorula }\end{array}$ & $\begin{array}{l}\text { this yeast strain. The fermentation time for the highest carotenoid } \\
\text { yield is observed after } 8 \text { days. }\end{array}$ \\
\hline
\end{tabular}

\section{Introduction}

Carotenoids such as $\beta$-carotene in carrots or lycopene in tomatoes are natural bioactive compounds which were often isolated from the plants. These compounds are not only antioxidants but also antimutagens. Currently, medical products containing carotenoids have become more and more popular in Vietnam and over the world.

Apart from the plants, strains of the genus Rhodotorula are also able to synthesize carotenoids. Researches on carotenoid biosynthesis by Rhodotorula began in the early 2000s. Rhodotorula yeasts can ferment sugar (glucose, xylose, saccharose,...), glycerol (Easterling, French, Hernandez, \& Licha, 2009; Gientka, Kieliszek, Jermacz, \& Błażejak, 2017) and industrial byproducts such as grape must (Buzzini, 2000), sugarcane molasses (Bhosale \& Gadre, 2001), cassava water (Silva et al., 2016), sugar beet molasses (Taskin, Sisman, Erdal, \& Kurbanoglu, 2011), potato wastewater (Kot et al., 2017).

These yeasts can biosynthesize both lipid and carotenoid. Some researchers optimized the carbon/nitrogen $(\mathrm{C} / \mathrm{N})$ ratio which obtained the highest yield of the lipid and carotenoid. Depending on the species of Rhodotorula, the optimal C/N ratio has been different. Production 
of carotenoid by $R$. gracilis reached its peak at $26 \mathrm{mg} / \mathrm{g}$ dry biomass weight with the $\mathrm{C} / \mathrm{N}$ ratio in the medium of 10:1 (Somashekar \& Joseph, 2000). Braunwald et al. (2013) studied the effect of $\mathrm{C} / \mathrm{N}$ ratios on carotenoid and lipid production of $R$. glutinis and showed that the increase of this ratio in the growth medium led to increased lipid and carotenoid yield.

Apart from $\mathrm{C} / \mathrm{N}$ ratios, other parameters in fermentation were concerned by researchers. Buzzini (2000) determined that the $\mathrm{pH} 5.78$ and yeast autolysate concentration $4.67 \mathrm{~g} / \mathrm{L}$ were the most appropriate for $R$. glutinis carotenoid production. In Cong, Chi, Li, and Wang's report (2007), the optimum parameters for the growth of $R$. sp. hidai were the medium containing $4 \mathrm{~g}$ sucrose, $1.5 \mathrm{~g}$ yeast extract, $0.1 \mathrm{~g} \mathrm{MgSO} 4$ and $100 \mathrm{~mL}$ seawater at $\mathrm{pH} 6.0$ and $30^{\circ} \mathrm{C}$ at which the carotenoid yield reached $603.93 \mu \mathrm{g} / \mathrm{g}$ dry cell weight. A study of parameters for carotenoid biosynthesis by $R$. gracilis indicated that maximum carotenogenesis $(0.09 \%)$ achieved at $8 \%$ glucose level, $\mathrm{pH} 7.5$ and $6.0 \mathrm{~mL} / 100 \mathrm{~mL}$ of inoculum for an incubation period of 12 days at $24^{\circ} \mathrm{C}$.

In this study, we characterized the effects of some nutritional and environmental parameters on the carotenoid production by Rhodotorula sp. through solid-state fermentation on corncobs in order to maximize the carotenoid production by the Rhodotorula sp. strain isolated from rice leaves.

\section{Materials and methods}

\subsection{Microorganism and culture conditions}

Rhodotorula sp. (MN12) which was isolated from rice leaves in Long An province was provided by the Institute of Biotechnology and Food Technology, Industrial University of HCM City.

The yeast was maintained on malt agar $(200 \mathrm{~g}$ ground malt, $20 \mathrm{~g}$ agar and $1 \mathrm{~L}$ distilled water) by subculturing every two weeks.

Cells grown for 48 hours in $250 \mathrm{~mL}$ shaken flasks containing $150 \mathrm{~mL}$ malt broth, harvested by centrifugation ( $3000 \mathrm{rpm}$ for $20 \mathrm{mins}$ ), washed and resuspended in $10 \mathrm{~mL}$ of sterile distilled water were used as inocula for fermentation studies.

\subsection{Fermentation conditions}

Corncobs were cut into small pieces and stored at $-180 \mathrm{C}$ until using. Corncob (30g) was thawed and put into thermostable plastic boxes (volume of $0.5 \mathrm{~L}$ ). Moreover, a nutrient solution consisting of glucose, $\mathrm{NaNO}_{3}, \mathrm{KH}_{2} \mathrm{PO}_{4}$ and $\mathrm{MgSO}_{4}$ was supplemented. After being sterilized at $121^{\circ} \mathrm{C}$ for $20 \mathrm{~min}$, the boxes were added inoculum and then fermentation was begun and lasted for 5-10 days at $30^{\circ} \mathrm{C}$.

\subsection{Carotenoid extraction and determination}

After incubation, the corncod $(30 \mathrm{~g})$ was shaken with distilled water $(150 \mathrm{~mL})$ in the $250 \mathrm{~mL}$ Erlenmeyer flask. The biomass was harvested by centrifugation and ground with glass powder $(1: 1 \mathrm{w} / \mathrm{w})$. A mixed solvent (acetonitrile: 2-propanol: ethyl acetate 4/4/2) was used to extract carotenoids. Cell density was determined by turbidity measurement using UV/Vis spectrophotometer at $610 \mathrm{~nm}$. Quantitative determination of carotenoids was carried out spectrophotometrically at $454 \mathrm{~nm}$. 


\section{Results and discussion}

\subsection{Effect of the C/N ratio on carotenoid biosynthesis}

The influence of the different $\mathrm{C} / \mathrm{N}$ ratios of the medium $(8: 1,16: 1 ; 24: 1 ; 32: 1$ and 40:1) on carotenoid production by the red yeast Rhodotorula sp. has been assessed and shown in Table 1.

\section{Table 1}

Carotenoid concentration was obtained in the mediums with different $\mathrm{C} / \mathrm{N}$ ratios

Carbon/nitrogen ratio

\begin{tabular}{cc}
\hline $8: 1$ & $23.36^{\mathrm{bc}}$ \\
\hline $16: 1$ & $18.12^{\mathrm{c}}$ \\
\hline $24: 1$ & $24.83^{\mathrm{bc}}$ \\
\hline $32: 1$ & $34.31^{\mathrm{ab}}$ \\
\hline $40: 1$ & $41.74^{\mathrm{a}}$ \\
\hline
\end{tabular}

Note: The different letters $(\mathrm{a}, \mathrm{b}, \mathrm{c})$ in the same column showed a significant difference in the carotenoid concentration

Source: The researcher's data analysis

In this experiment, the increase of $\mathrm{C} / \mathrm{N}$ ratio enhanced carotenoid production. Specifically, the carotenoid yield of Rhodotorula sp. at C/N ratios of 8:1, 16:1; 24:1; 32:1 and 40:1 were $23.36,18.12,24.83,34.31$ and $41.74 \mu$ g carotenoid /g dry matrix weight, respectively (Table 1). The carotenoid concentrations at $\mathrm{C} / \mathrm{N}$ ratios of 32:1 and 40:1 were not significantly different from each other, but higher than those at lower $\mathrm{C} / \mathrm{N}$ ratios. Many studies proved a correlation between $\mathrm{C} / \mathrm{N}$ ratio and carotenoid production. In a previous report, Rhodotorula gracilis gained the maximum carotenoid production in the medium with the $\mathrm{C} / \mathrm{N}$ ratio of 10:1 (Somashekar \& Joseph, 2000). Moreover, Libkind, Brizzio, and Van Broock (2004) achieved the highest level of carotenoid biosynthesis by $R$. mucilaginosa at the $\mathrm{C} / \mathrm{N}$ ratio of 5 . Therefore, both 32: and 40:1 C/N ratios are appropriate for our solid-state fermentation medium.

\subsection{Effect of the nitrogen concentration on carotenoid biosynthesis}

The carotenoid yields which were obtained in the mediums with six different nitrogen concentrations $(100-600 \mu \mathrm{g} / \mathrm{g}$ dry matrix weight) were compared with each other. In the range from 100 to $500 \mu \mathrm{g} / \mathrm{g}$ dry matrix weight, carotenoid content produced by Rhodotorula sp. increased with nitrogen concentration. At a higher concentration of nitrogen $(600 \mu \mathrm{g} / \mathrm{g}$ dry matrix weight), the carotenoid content remained the same as at $500 \mu \mathrm{g} / \mathrm{g}$ dry matrix weight (Table 2). Therefore, the nitrogen concentration of $500 \mu \mathrm{g} / \mathrm{g}$ dry matrix weight was chosen for further studies. 


\section{Table 2}

Carotenoid concentration in the mediums with different nitrogen concentration

\begin{tabular}{cc}
\hline $\begin{array}{c}\text { Nitrogen concentration } \\
(\boldsymbol{\mu g} / \mathbf{g} \text { matrix })\end{array}$ & $\begin{array}{c}\text { Carotenoid concentration } \\
(\boldsymbol{\mu g} / \mathbf{g} \text { matrix })\end{array}$ \\
\hline 100 & $28.99^{\mathrm{a}}$ \\
\hline 200 & $28.14^{\mathrm{a}}$ \\
\hline 300 & $31.03^{\mathrm{a}}$ \\
\hline 400 & $30.05^{\mathrm{a}}$ \\
\hline 500 & $54.71^{\mathrm{b}}$ \\
\hline 600 & $53.96^{\mathrm{b}}$
\end{tabular}

Note: The different letters $(a, b, c)$ in the same column showed a significant difference in the carotenoid concentration

Source: The researcher's data analysis

\subsection{Effect of the inoculum on carotenoid biosynthesis}

The range of inoculum from 10 to $10^{6} \mathrm{CFU} / \mathrm{g}$ dry matrix weight was used to characterize the effect of initial yeast density on carotenoid production by Rhodotorula sp. The data on carotenoid concentration which was obtained according to initial yeast density were shown in Table 3.

\section{Table 3}

Carotenoid concentration in the mediums with different initial yeast density

\begin{tabular}{cc}
\hline $\begin{array}{c}\text { Initial yeast density } \\
(\text { CFU/g matrix })\end{array}$ & $\begin{array}{c}\text { Carotenoid concentration } \\
(\boldsymbol{\mu g} / \mathbf{g} \text { matrix })\end{array}$ \\
\hline 10 & $27.00^{\mathrm{a}}$ \\
\hline $10^{2}$ & $24.80^{\mathrm{a}}$ \\
\hline $10^{3}$ & $27.85^{\mathrm{a}}$ \\
\hline $10^{4}$ & $36.23^{\mathrm{b}}$ \\
\hline $10^{5}$ & $38.68^{\mathrm{b}}$ \\
\hline $10^{6}$ & $37.16^{\mathrm{b}}$ \\
\hline
\end{tabular}

Note: The different letters $(a, b, c)$ in the same column showed the significant difference of the carotenoid concentration

Source: The researcher's data analysis 
Yeast fermentations starting from $10^{4}$ to $10^{6} \mathrm{CFU} / \mathrm{g}$ dry matrix weight resulted in a higher carotenoid accumulation than those starting from 10 to $10^{3} \mathrm{CFU} / \mathrm{g}$ dry matrix weight. When the initial yeast density was in the range of $10^{4}$ to $10^{6} \mathrm{CFU} / \mathrm{g}$ gram of dry matrix weight, the carotenoid yield obtained remained unchanged. Hence, the optimal inoculum for carotenoid production by Rhodotorula sp. is $10^{4} \mathrm{CFU} / \mathrm{g}$ dry matrix weight.

\subsection{Effect of matrix moisture on carotenoid biosynthesis}

The solid-state fermentation has been a method of incubating microorganisms requiring oxygen for their growth. Some agricultural byproducts can be utilized as nutrient supplies and biomass carriers, especially for yeasts and molds.

In this fermentation method, water contents in matrices have been an important parameter. In this study, the matrix moisture between $50 \%$ and $90 \%$ were studied.

\section{Table 4}

Carotenoid concentration in the mediums with different moisture conditions

\begin{tabular}{cc}
\hline Matrix moisture $(\%)$ & $\begin{array}{c}\text { Carotenoid concentration } \\
(\boldsymbol{\mu g} / \mathbf{g} \text { dry matrix weight })\end{array}$ \\
\hline 50 & $17.06^{\mathrm{a}}$ \\
\hline 60 & $14.96^{\mathrm{a}}$ \\
\hline 70 & $26.22^{\mathrm{a}}$ \\
\hline 80 & $69.38^{\mathrm{b}}$ \\
\hline 90 & $73.99^{\mathrm{b}}$ \\
\hline
\end{tabular}

Note: The different letters $(a, b, c)$ in the same column showed a significant difference in the carotenoid concentration

Source: The researcher's data analysis

As shown in Table 4, the matrix moisture significantly influenced the carotenoid yield. When the water content changed from 50 to $70 \%$, the difference of carotenoid synthesis was not clear. The yield of carotenoids increased significantly at the moisture content of $80 \%$ and the carotenoid yield stably remained when the moisture content has risen to $90 \%$.

\subsection{The carotenoid production during in 10-day incubation period}

With the optimal parameters in the previous experiments, the fermentation was carried out after 10 days. The carotenoid yields were collected and determined every day. As described in Figure 1, carotenoid production can be divided into three phases. In the first phase (the first 5 days), the carotenoid production significantly increased from 0 to $66.02 \mu \mathrm{g} / \mathrm{g}$ dry matrix weight. In the second phase (the next 3 days), the carotenoid yield continued increasing but at a lower rate than in the first phase. In the last phase, the carotenoid production decreased to $34.41 \mu \mathrm{g} / \mathrm{g}$ dry matrix weight. Therefore, in these solid-state fermentation conditions, the time for carotenoid biosynthesis is around 6 to 8 days, when the carotenoid yield reaches the maximum level. 


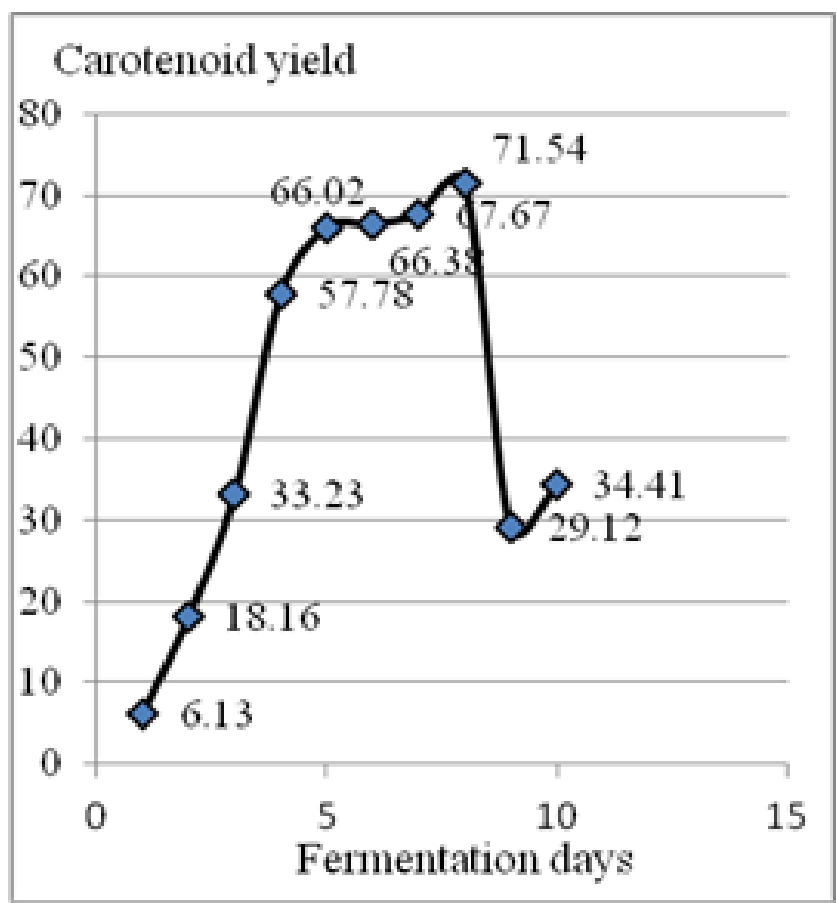

Figure 1. Carotenoid yield during 10-day fermentation period

Our study is in line with literature data on fermentation conditions that have been reported. When using rice bran as a sole substrate for Rhodotorula cultivation, the carotenoid accumulation reached the highest level at the moisture content of $70 \%$ (Roadjanakamolson \& Suntornsuk, 2010). Additionally, Hernandez-Almaza, Montanez-Saenza, Martınez-Avilab, Rodriguez-Herreraa, and Aguilar (2014) used ground polyurethane foam as the support for another strain of Rhodotorula which produced carotenoid. In that work, some ranges of fermentation conditions were studied in order to find out the optimized parameters of moisture (70 - 90\%), fermentation time (48-72h) and inoculum $\left(10^{6}-10^{8}\right)$.

\section{Conclusion}

The Rhodotorula strain, which was isolated from rice leaves in this study, could synthesize carotenoid with the $\mathrm{C} / \mathrm{N}$ ratio of $32: 1$; nitrogen concentration of $500 \mu \mathrm{g} / \mathrm{g}$ dry matrix weight; matrix moisture of $80 \%$ and the initial inoculum of $10^{4} \mathrm{CFU} / \mathrm{g}$ dry matrix weight. The biomass harvested after 8-day fermentation reached the highest yield of carotenoids $(71.54 \mu \mathrm{g} / \mathrm{g}$ dry matrix weight). Our study would provide a basic assessment for optimization of nutrient and environmental conditions on carotenoid biosynthesis by Rhodotorula $s p$.

\section{ACKNOWLEDGEMENT}

I would like to express my great appreciation to the Laboratory of Biochemistry and Food Technology Division, Ho Chi Minh City University of Technology for supporting us in our project. I would also like to extend my thanks to the technicians of the Faculty of Biotechnology, Ho Chi Minh City Open University for their help in offering me the resources in running the experiments. 


\section{References}

Bhosale, P., \& Gadre, R.V. (2001). Beta-carotene production in sugarcane molasses by A Rhodotorula glutinis mutant. Journal of Industrial Microbiology \& Biotechnology, 26, 327-332.

Braunwald, T., Schwemmlein, L., Graeff-Hönninger, S., French, W. T., Hernandez, R., Holmes, W. E., \& Claupein, W. (2013). Effect of different C/N ratios on Carotenoid and lipid production by Rhodotorula glutinis. Applied Microbiology and Biotechnology, 97, 6581-6588. doi:10.1007/s00253-013-5005-8

Buzzini, P. (2000). An optimization study of carotenoid production by Rhodotorula glutinis from substrates containing concentrated rectified grape must as the sole carbohydrate source. Journal of Insdustrial Microbiology \& Biotechnology, 24, 41-45.

Chandi, G. K., Singh, S. P., Gill, B. S., Sogi, D. S., \& Singh, P. (2010). Optimization of carotenoids by Rhodotorula glutinis. Food Science and Biotechnology, 19(4), 881-887.

Gientka, I., Kieliszek, M., Jermacz, K., \& Błażejak, S. (2017). Identification and characterization of oleaginous yeast isolated from kefir and its ability to accumulate intracellular fats in deproteinated potato wastewater with different carbon sources. Biomed Research International, 2017, Article 6061042. doi:10.1155/2017/6061042

Cong, L., Chi, Z., Li, J., \& Wang, X. (2007). Enhanced carotenoid production by a mutant of the marine yeast Rhodotorula sp. hidai. Journal of Ocean University of China (Oceanic and Coastal Sea Research), 6(1), 66-71.

Govindaswamy, V., Vasudevan, V., \& Divakar, S. (1998). Optimisation of growth parameters for the production of carotenoids by Rhodotorula gracilis. Z Lebensm Unters Forsch A, 208, 121-124.

Easterling, E. R., French, W. T., Hernandez, R., \& Licha, M. (2009). The effect of glycerol as a sole and secondary substrate on the growth and fatty acid composition of Rhodotorula glutinis. Bioresource Technology, 100(1), 356-361.

Hernandez-Almanzaa, A., Montanez-Saenza, J., Martınez-Avilab, C., Rodriguez-Herreraa, R., \& Aguilar, C. N. (2014). Carotenoid production by Rhodotorula glutinis YB-252 in solidstate fermentation. Food Bioscience, 7, 31-36.

Kim, S. G., Chu, K. H., \& Kim E. Y. (2011). Determination of optimum fermentation conditions for carotenoid production by Rhodotorula aurantiaca K-505. Korean Journal of Chemical Engineering, 28(1), 216-220.

Kot, A. M., Kurcz, A., Bry, J., Gientka, I., Bzducha-wróbel, A., Maliszewska, M., \& Reczek, L. (2017). Effect of initial pH of medium with potato wastewater and glycerol on protein, lipid and carotenoid biosynthesis by Rhodotorula glutinis. Electronic Journal of Biotechnology, 27, 25-31. doi:10.1016/j.ejbt.2017.01.007

Libkind, D., Brizzio, S., \& Van Broock, M. (2004). Rhodotorula mucilaginosa, a carotenoid producing yeast strain from a patagonian high-altitude lake. Folia Microbiol, 49(1), 1925.

Park, P. K., Cho, D. H., Kim, E. Y., \& Chu, K. H. (2005). Optimization of carotenoid production by Rhodotorula glutinis using statistical experimental design. World Journal of Microbiology \& Biotechnology, 21, 429-434. 
Petrik, S., Marova, I., Haronikova, A., Kostovova, I., \& Breierova, E. (2013). Production of biomass, carotenoid and other lipid metabolites by several red yeast strains cultivated on waste glycerol from biofuel production - A comparative screening study. Annals of Microbiology, 63, 1537-1551.

Roadjanakamolson, M., \& Suntornsuk, W. (2010), Production of $\beta$-carotene-enriched rice bran using solid-state fermentation of rhodotorula glutinis. Journal of Microbiolog and Biotechnology, 20(3), 525-531.

Silva, R. S., Moura, E. F., de Farias Neto, J. T., Sousa, N. R., Moura, M. F., \& Sampaio, J. E. (2016). Genetic divergence among accessions of cassava (Manihot esculenta Crantz) sampled in the Tapajós region, State of Pará, using agronomic characters and microsatellite markers. The Journal Semina Ciencias Agrarias, 37(5), 2989-3004.

Somashekar, D., \& Joseph, R. (2000). Inverse relationship between carotenoid and lipid formationin Rhodotorula gracilis according to the $\mathrm{C} / \mathrm{N}$ ratio of the growth medium. World Journal of Microbiology \& Biotechnology, 16, 491-493.

Taskin, M., Sisman, T., Erdal, S., \& Kurbanoglu, E. B. (2011). Use of waste chicken feathers as peptone for production of carotenoids in submerged culture of Rhodotorula glutinis MT-5. European Food Research and Technology, 233, 657-665.

Vijayalakshmi, G., Shobha, B., Vanajakshi, V., Divakar, S., \& Manohar, B. (2001). Response surface methodology for optimization of growth parameters for the production of carotenoids by a mutant strain of Rhodotorula gracilis. European Food Research and Technology, 213, 234-239.

Wang, S. L., Sun, J. S., Han, B. Z., \& Wu, X. Z. (2008). Enhanced $\beta$-carotene production by Rhodotorula glutinis using high hydrostatic pressure. Korean Journal of Chemical Engineering, 25(3), 513-516.

Yadav, S. K., \& Prabha, R. (2014). Effect of pH and temperature on carotenoid pigments produced from Rhodotorula minuta. International Journal of Fermented Foods, 3(2), 105-113. 